\author{
Martin C. J. Kneyber \\ Mohammed I. Hersi \\ Jos W. R. Twisk \\ Dick G. Markhorst \\ Frans B. Plötz
}

\section{Red blood cell transfusion in critically ill children is independently associated with increased mortality}

Received: 12 July 2006

Accepted: 11 May 2007

Published online: 16 June 2007

(C) Springer-Verlag 2007

M. C. J. Kneyber $(\varangle) \cdot$ M. I. Hersi •

D. G. Markhorst · F. B. Plötz

VU University Medical Center, Department of Pediatric Intensive Care, Office 8 D 12 , P.O. Box 7057, 1007 MB Amsterdam, The Netherlands e-mail: m.kneyber@vumc.nl Tel.: +31-20-4442413

Fax: +31-20-4443045

J. W. R. Twisk

VU University Medical Center, Department of Clinical Epidemiology and Biostatistics, P.O. Box 7057, 1007 MB Amsterdam, The Netherlands

\begin{abstract}
Objective: To test the hypothesis that RBC transfusion in critically ill children is independently
\end{abstract}

associated with increased mortality and morbidity. Design: Retrospective, descriptive epidemiologic cohort study. Setting: Single-center experience of a nine-bed pediatric intensive care unit (PICU) facility. Patients: Critically ill children without ongoing active blood loss aged 0 months to 18 years, excluding prematurely born infants or patients after cardiothoracic surgery, and patients with chronic anemia. Interventions: None. Measurements and Results: Data of 295 consecutive patients was studied. Of these patients, $13.4 \%$ had a Hb concentration less than $9.6 \mathrm{~g} / \mathrm{dl}$. Sixty-seven $(22.7 \%)$ of all patients were transfused, 39 only once. Transfused patients had a higher mortality (16.4 vs. $2.6 \%, p<0.001)$. Mortality seemed related to the number of transfusion $(p=0.002)$ rather than the pre-transfusion $\mathrm{Hb}$ concentration $(p=0.10)$. Transfused patients required prolonged ventilatory sup- port $(11.1 \pm 1.8$ vs. $3.2 \pm 0.3$ days, $p<0.001$ ), infusion of vaso-active agents $(8.2 \pm 1.8$ vs. $2.8 \pm 0.6$ days, $p<0.001)$ and PICU stay $(13.0 \pm 1.8$ vs. $3.2 \pm 0.2$ days, $p<0.001)$. After multivariate analysis adjusting for age, PIM probability of death, mean TISS-28 score during the first $48 \mathrm{~h}$, post-operative admission, diagnosis of sepsis or trauma or malignancy, pre-transfusion $\mathrm{Hb}$ concentration, and RBC transfusion remained independently associated with mortality and morbidity. Conclusions: RBC transfusion in critically ill children is independently associated with increased mortality and prolonged duration of mechanical ventilation, prolonged infusion of vaso-active agents and prolonged PICU stay.

Keywords Critically ill children . Erythrocyte transfusions - Mortality · Outcome assessment

\section{Introduction}

The practice of red blood cell (RBC) transfusion in critically ill children is common [1-3]. From a retrospective survey among five pediatric intensive care units (PICU) in the United States it was found that 54.5\% of all children with a pre-transfusion hemoglobin $(\mathrm{Hb})$ concentration below $9 \mathrm{~g} / \mathrm{d}$ l received one or more RBC transfusions [4]. Nevertheless, a well-defined threshold value of hemoglobin $(\mathrm{Hb})$ used for the decision as to when to transfuse or not is unavailable [5].

An increasing number of prospective and retrospective (observational) studies in a heterogeneous group of critically ill adults show that RBC transfusions are independently associated with increased morbidity and mortality, irrespective of disease severity defined by admitting APACHE II and SOFA scores [6-16]. It is unknown whether this is also true for critically ill children. 
The objective of our observational study therefore was to test the hypothesis that RBC transfusion in a heterogeneous group of critically ill children admitted to a medicosurgical pediatric ICU (PICU) is independently associated with increased mortality and morbidity, irrespective of pretransfusion $\mathrm{Hb}$ and disease severity.

\section{Materials and methods}

Study design

The study was designed as a retrospective, single-center observational study. The need for informed consent was waived by the institutional review board.

\section{Patients and setting}

Records from all children aged 0 months to 18 years admitted to the PICU of our hospital were obtained, irrespective of pre-transfusion $\mathrm{Hb}$ concentration. We chose to study patients admitted between January and December 2003, because as of January 2002 all RBC concentrates were leukocyte-depleted in The Netherlands. Anemia was defined by a $\mathrm{Hb}$ concentration below $9.6 \mathrm{~g} / \mathrm{dl}$ as described previously $[1,17]$. Children diagnosed with chronic anemia (defined by the presence of anemia for more than 6 weeks), children with hemoglobinopathies, and children with active blood loss were excluded. Our PICU is a combined medical and surgical tertiary nine-bed facility that includes all specialties except the care for prematurely born infants (these patients are admitted to the neonatal intensive care unit of our hospital) and patients after cardiothoracic surgery.

\section{Data collection}

For each patient demographical and clinical data, including type of admission, primary diagnostic category, history of anemia and recent acute blood loss, pre-transfusion hemoglobin $(\mathrm{Hb})$ concentration or first $\mathrm{Hb}$ concentration for non-tranfused patients, number of erythrocyte transfusions, and volume transfused, was noted. Our unit did not have a transfusion guideline. The decision to transfuse a patient was made by the attending physician. Routinely, the quantity per erythrocyte transfusion amounts to $10-15 \mathrm{ml} / \mathrm{kg}$.

Disease severity upon PICU admission was defined by the Pediatric Index of Mortality (PIM) probability of death. The PIM score is composed of variables that are noted during the first hour of PICU admission. For this study the PIM score was retrospectively calculated. Data on all variables necessary for this score were available in all patients. This score reflects the severity of disease and have been validated [18]. Additionally, the TISS-28 score was calculated for the first 2 days of PICU admission. TISS-28 is a scoring system composed of 28 therapeutic activities that can be used to assess severity of illness [19]. The TISS-28 score is prospectively calculated on a daily basis in our unit.

\section{Definition of outcome}

The PICU mortality was the primary outcome. Morbidity as secondary outcome was defined by duration of mechanical ventilation (MV), duration of infusion of vasoactive agents including dopamine, dobutamine, and norepinephrine, and duration of PICU stay.

\section{Statistical analysis}

In the univariate analysis demographical and clinical data were compared between patients who were transfused and those who were not. For continuous variables the MannWhitney U-test was used, and for categorical variables the $\chi^{2}$ test or Fisher's exact test. Missing variables were not imputed.

Subsequently, we wanted to the estimate the independent contribution of RBC transfusion to each outcome parameter. We therefore applied multiple logistic regression analysis for the primary outcome (mortality, which is dichotomous data), and Cox proportional hazards regression analysis for the secondary outcome measures (duration of infusion of vaso-active agents, mechanical ventilation and PICU stay, which are continuous data). Regression analysis estimates how confounders are related to the outcome and produces an adjusted estimate of the intervention effect [20]. To adjust for disease severity upon PICU admission, we adjusted for PIM probability of death. To adjust for confounding by indication, we adjusted for the mean TISS-28 score during the first $48 \mathrm{~h}$ after PICU admission. Finally, we also adjusted for pretransfusion $\mathrm{Hb}$ concentration, admission post-operatively, and admission diagnosis. Each potential confounding variable was separately entered into the model.

To study if RBC transfusion would lead to an excess in mortality, we also calculated the Standardized Mortality Ratio (SMR) for five probability of death strata calculated from the PIM score. The SMR is calculated by dividing the observed number of deaths by the expected number of deaths per strata. The expected number of deaths was obtained from the Dutch Working Group on Pediatric Intensive Care Evaluation (PICE).

All statistical analyses were performed with SPSS version 13 (Chicago, Ill.). The $p$-values below 0.05 were accepted as statistically significant. Data are expressed as mean \pm standard error unless otherwise stated. 


\section{Results}

Description of the study population

During the study period a total number of 295 consecutive patients were admitted. No patients met the exclusion criteria. In addition, there were no patients with ongoing active blood loss as cause of anemia.

One hundred sixteen patients $(39.3 \%)$ were admitted after a surgical procedure. Mechanical ventilation was required in 123 patients $(41.7 \%)$. Forty-two (14.2\%) patients required continuous infusion of vaso-active agents. Data on pre-transfusion $\mathrm{Hb}$ or first $\mathrm{Hb}$ upon PICU admission could be retrieved in 261 (88.5\%) patients. Anemia occurred in $13.8 \%$ of all patients. Severe anemia $(\mathrm{Hb}<7 \mathrm{~g} / \mathrm{dl})$ occurred in $7(2.7 \%)$ of all patients. Sixtyseven $(22.7 \%)$ patients were transfused; $39(58.2 \%)$ were transfused only once. Seventeen patients (5.8\%) died.

\section{Univariate analysis}

Table 1 summarizes the differences in demographical and clinical variables between patients who received
Table 1 Differences in unadjusted analysis between patients who received one or more red blood cell (RBC) transfusions and patients who were not transfused. PIM, Pediatric Index of Mortality;
$I Q R$, interquartile range. Continuous variables are presented as mean \pm standard error, categorical variables are presented as absolute number $(n)$ or frequency $(\%)$

\begin{tabular}{|c|c|c|c|}
\hline & $\begin{array}{l}\text { RBC transfusion } \\
\text { Yes }(n=67)\end{array}$ & No $(n=228)$ & $p$-value \\
\hline Age (months), median (25-75 IQR) & $65.4 \pm 8.0(38.9 ; 8.3-115.1)$ & $71.4 \pm 11.7(29.2 ; 4.0-112.6)$ & 0.336 \\
\hline Boys/girls (\%) & $59.7 / 40.3$ & $58.3 / 41.7$ & 0.842 \\
\hline PIM probability of death $(\%)$ & $4.6 \pm 1.1$ & $1.7 \pm 0.3$ & $<0.001$ \\
\hline Mean TISS during first $48 \mathrm{~h}$ & $24 \pm 2$ & $15 \pm 1$ & $<0.001$ \\
\hline Hemoglobin (g/dl) ${ }^{\text {a }}$, median (25-75 IQR) & $9.6 \pm 0.2(9.3 ; 8.2-10.6)$ & $13.0 \pm 0.2(12.4 ; 11.0-13.7)$ & $<0.001$ \\
\hline \multicolumn{4}{|l|}{ Admission diagnosis $(n)^{b}$} \\
\hline Post-operative & 23 & 93 & 0.41 \\
\hline Infectious diseases ${ }^{c}$ & 22 & 59 & 0.26 \\
\hline Trauma & 9 & 13 & 0.034 \\
\hline Septic shock & 4 & 3 & 0.05 \\
\hline Malignancy & 6 & 7 & 0.039 \\
\hline Miscellaneous & 3 & 54 & $<0.001$ \\
\hline
\end{tabular}

${ }^{\mathrm{a}}$ For transfused patients the number represents the pre-transfusion $\mathrm{Hb}$, for non-transfused patients it represents $\mathrm{Hb}$ at admission; ${ }^{\mathrm{b}} \mathrm{When}$ the count of any cell was below five, the Fisher's exact test was used; ${ }^{c}$ Included all infectious causes irrespective of organ system

Table 2 Results from unadjusted analysis on the primary and secondary outcomes. PICU, pediatric intensive care unit. Continuous variable are presented as mean \pm standard error, categorical variables are presented as frequency $(\%)$

\begin{tabular}{|c|c|c|c|c|}
\hline & $\begin{array}{l}\text { No. of patients } \\
\text { (transfused/not transfused) }\end{array}$ & $\begin{array}{l}\mathrm{RBC} \\
\text { transfusion }\end{array}$ & $\begin{array}{l}\text { No RBC } \\
\text { transfusion }\end{array}$ & $p$-value \\
\hline \multicolumn{5}{|l|}{ All patients $(n=295)$} \\
\hline Vaso-active support (days) & $27 / 15$ & $8.2 \pm 1.8$ & $2.8 \pm 0.6$ & 0.043 \\
\hline Mechanical ventilation (days) & $59 / 64$ & $11.1 \pm 1.8$ & $3.2 \pm 0.3$ & $<0.001$ \\
\hline PICU stay (days) & $67 / 228$ & $13.0 \pm 1.8$ & $3.2 \pm 0.2$ & $<0.001$ \\
\hline Mortality (\%) & $67 / 228$ & 16.4 & 2.6 & $<0.001$ \\
\hline \multicolumn{5}{|c|}{ Patients not admitted post-operatively ( $n=179$ ) } \\
\hline Vaso-active support (days) & $20 / 12$ & $7.7 \pm 1.9$ & $3.2 \pm 2.4$ & 0.083 \\
\hline Mechanical ventilation (days) & $39 / 39$ & $11.5 \pm 2.2$ & $3.6 \pm 0.5$ & $<0.001$ \\
\hline PICU stay (days) & $44 / 135$ & $14.1 \pm 2.2$ & $3.6 \pm 0.3$ & $<0.001$ \\
\hline Mortality $(\%)$ & $44 / 135$ & 15.9 & 4.4 & 0.011 \\
\hline \multicolumn{5}{|c|}{ Patients with a PICU stay $>2$ days $(n=133)$} \\
\hline Vaso-active support (days) & $23 / 8$ & $9.5 \pm 1.9$ & $4.0 \pm 0.9$ & 0.219 \\
\hline Mechanical ventilation (days) & $48 / 40$ & $13.4 \pm 2.0$ & $3.8 \pm 0.5$ & $<0.001$ \\
\hline PICU stay (days) & $51 / 82$ & $16.5 \pm 2.1$ & $5.4 \pm 0.4$ & $<0.001$ \\
\hline Mortality $(\%)$ & $51 / 82$ & 17.6 & 3.7 & 0.006 \\
\hline \multicolumn{5}{|c|}{ Patients without a high-risk diagnosis (sepsis and/or malignancy; $n=278$ ) } \\
\hline Vaso-active support (days) & $21 / 15$ & $8.2 \pm 2.1$ & $2.8 \pm 0.6$ & 0.096 \\
\hline Mechanical ventilation (days) & $52 / 64$ & $11.4 \pm 1.9$ & $3.2 \pm 0.3$ & $<0.001$ \\
\hline PICU stay (days) & $57 / 221$ & $12.9 \pm 2.0$ & $3.2 \pm 0.2$ & $<0.001$ \\
\hline Mortality (\%) & $57 / 221$ & 15.8 & 2.7 & $<0.001$ \\
\hline
\end{tabular}


Fig. 1 Differences in survival by pre-transfusion $\mathrm{Hb}$, or first $\mathrm{Hb}$ if not transfused. [Data on pre-transfusion $\mathrm{Hb}$ or first $\mathrm{Hb}$ upon PICU admission available in $261(88.5 \%)$ patients]

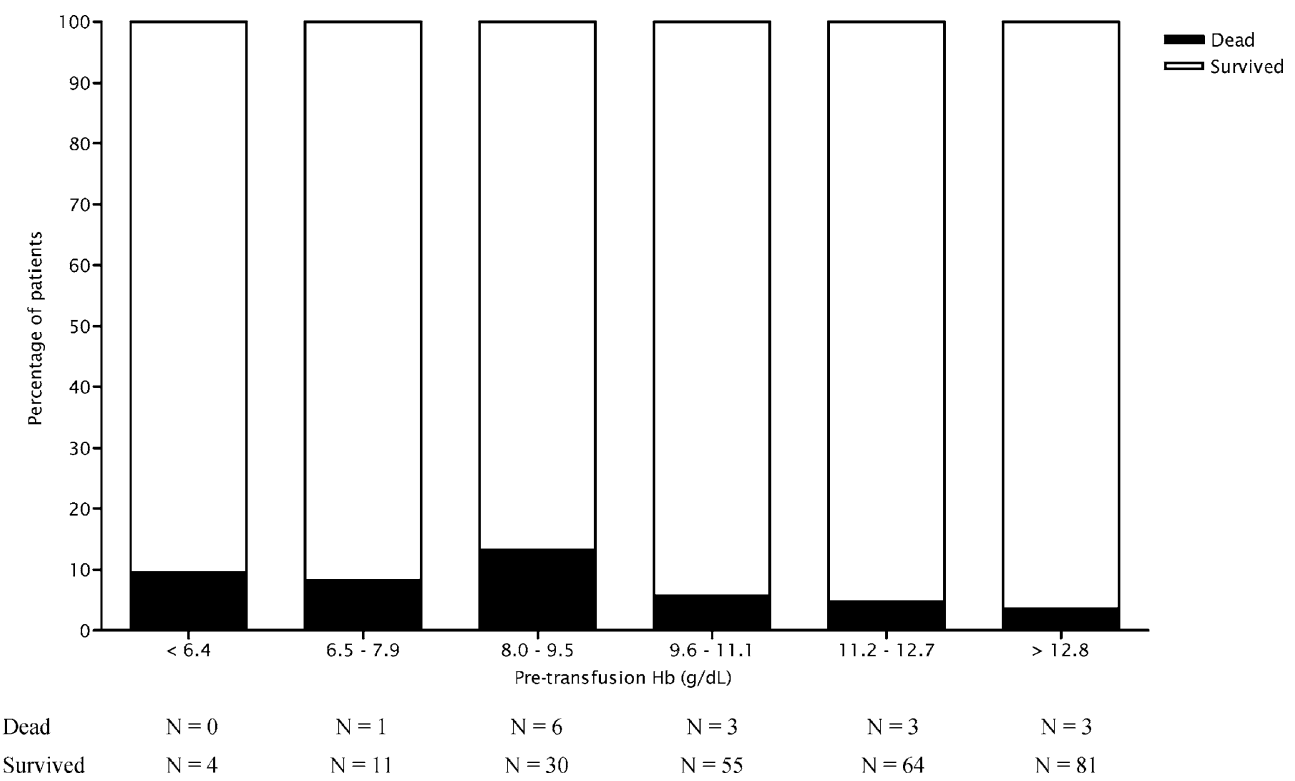

Table 3 Results from the logistic regression analysis on the association between RBC transfusion and mortality. Adjustments were made for PIM probability of death, mean TISS-28 score during the

first $48 \mathrm{~h}$ of PICU admission, post-operative admission, presence of sepsis and/or malignancy, and pre-transfusion hemoglobin concentration. $O R$, odds ratio; $C I$, confidence interval of the $\mathrm{OR}$

\begin{tabular}{|c|c|c|c|}
\hline Variable & Odds ratio & $95 \% \mathrm{CI}$ & $p$-value \\
\hline $\begin{array}{l}\text { Full model } \\
\text { PIM probability of death } \\
\text { Mean TISS-28 } \\
\text { Sepsis and/or malignancy } \\
\text { Post-operative admission } \\
\text { Pre-transfusion } \mathrm{Hb}(\mathrm{g} / \mathrm{dl}) \\
\text { RBC transfusion }\end{array}$ & $\begin{array}{l}1.087 \\
1.043 \\
1.103 \\
0.845 \\
1.228 \\
9.951\end{array}$ & $\begin{array}{l}1.019-1.159 \\
0.978-1.113 \\
0.092-13.161 \\
0.178-4.011 \\
0.944-1.597 \\
1.283-77.157\end{array}$ & $\begin{array}{l}0.011 \\
0.202 \\
0.938 \\
0.832 \\
0.125 \\
0.028\end{array}$ \\
\hline $\begin{array}{l}\text { Bivariate analysis } \\
\text { Adjusting for PIM probabilit } \\
\text { PIM probability of death } \\
\text { RBC transfusion }\end{array}$ & $\begin{array}{l}1.097 \\
5.730\end{array}$ & $\begin{array}{l}1.033-1.165 \\
1.892-17.351\end{array}$ & $\begin{array}{l}0.002 \\
0.002\end{array}$ \\
\hline $\begin{array}{l}\text { Adjusting for mean TISS-28 } \\
\text { Mean TISS-28 } \\
\text { RBC transfusion }\end{array}$ & $\begin{array}{l}\text { of PICU adn } \\
1.036 \\
4.699\end{array}$ & $\begin{array}{l}0.979-1.096 \\
1.144-19.302\end{array}$ & $\begin{array}{l}0.224 \\
0.032\end{array}$ \\
\hline $\begin{array}{l}\text { Adjusting for presence of sep } \\
\text { Sepsis and/or malignancy } \\
\text { RBC transfusion }\end{array}$ & $\begin{array}{l}\text { cy }(n=295) \\
1.134 \\
7.157\end{array}$ & $\begin{array}{l}0.220-5.839 \\
2.486-20.603\end{array}$ & $\begin{array}{r}0.881 \\
<0.001\end{array}$ \\
\hline $\begin{array}{l}\text { Adjusting for post-operative } \\
\text { Post-operative admission } \\
\text { RBC transfusion }\end{array}$ & $\begin{array}{l}0.495 \\
7.065\end{array}$ & $\begin{array}{l}0.153-1.603 \\
2.496-20.001\end{array}$ & $\begin{array}{r}0.241 \\
<0.001\end{array}$ \\
\hline $\begin{array}{l}\text { Adjusting for pre-transfusion } \mathrm{H} \\
\text { Pre-transfusion } \mathrm{Hb}(\mathrm{g} / \mathrm{dl}) \\
\text { RBC transfusion }\end{array}$ & $\begin{array}{l}1.106 \\
9.309\end{array}$ & $\begin{array}{l}0.776-1.577 \\
2.369-36.587\end{array}$ & $\begin{array}{l}0.576 \\
0.001\end{array}$ \\
\hline
\end{tabular}

Hosmer and Lemeshow Goodness-of-fit test for the full model, $\chi^{2}$ test 4.308 with 8 degrees of freedom, $p=0.828$

one or more RBC transfusions and those who were not transfused. Gender distribution and mean age were not different between the two groups. We noted a significantly higher mean PIM probability of death among transfused patients, indicating that they were more severely ill. We also found a significantly higher mean TISS-28 score during the first $48 \mathrm{~h}$ of PICU admission.
Table 2 summarizes the difference between patients with and without RBC transfusion on primary and secondary outcome measures. Among patients who had received one or more $\mathrm{RBC}$ transfusions a higher mortality rate ( 16.4 vs. $2.6 \%, p<0.001)$ was observed. Importantly, we observed no association between the pre-transfusion $\mathrm{Hb}$ concentration and mortality $(p=0.10)$ as can be seen 
Fig. 2 Differences in survival by number of red blood cell transfusions
Table 4 Results from the Cox proportional hazards regression analysis on the association between RBC transfusion and duration of infusion of vaso-active agents $(n=42$ patients). Adjustments were made for age, PIM probability of death, mean TISS-28 score during the first $48 \mathrm{~h}$ of PICU admission, post-operative admission, presence of sepsis or malignancy, and pre-transfusion hemoglobin concentration. $\beta$, coefficient's estimate; $C I$, confidence interval

Table 5 Results from the Cox proportional hazards regression analysis on the association between RBC transfusion and duration of mechanical ventilation ( $n=123$ patients) Adjustments were made for age, PIM probability of death, mean TISS-28 score during the first $48 \mathrm{~h}$ of PICU admission, post-operative admission, presence of sepsis or malignancy, and pre-transfusion hemoglobin concentration. $\beta$, coefficient's estimate; $C I$, confidence interval

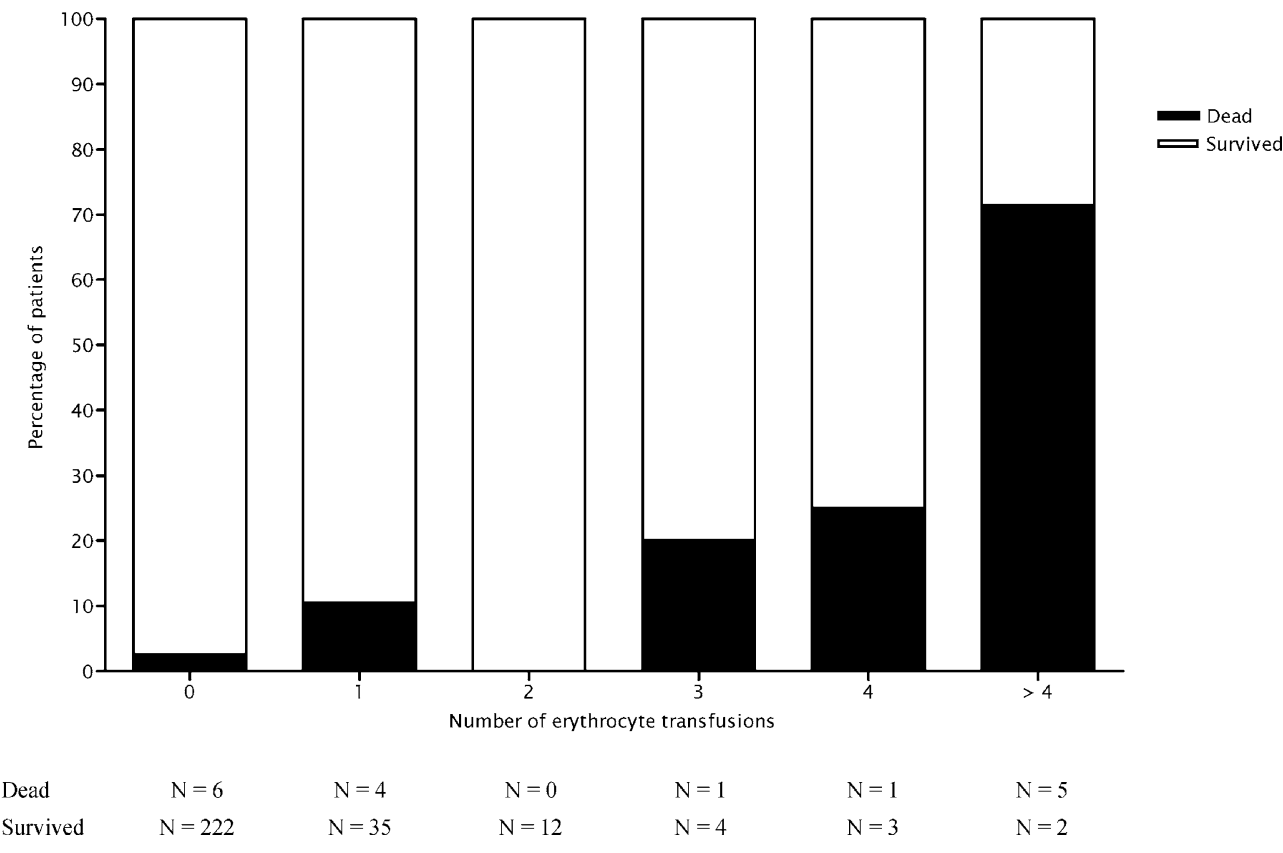

\begin{tabular}{llll}
\hline Variable & Hazard & $95 \%$ CI & $p$-value \\
\hline PIM probability of death $(\%)$ & 0.979 & $0.889-1.078$ & 0.665 \\
Mean TISS-28 first 48 $\mathrm{h}$ & 1.022 & $0.990-1.055$ & 0.175 \\
Pre-transfusion Hb concentration (mmol/l) & 0.956 & $0.214-4.277$ & 0.954 \\
Post-operative admission (yes/no) & 0.693 & $0.226-2.122$ & 0.521 \\
Presence of sepsis/malignancy (yes/no) & 1.012 & $0.799-1.283$ & 0.918 \\
RBC transfusion & 3.366 & $1.111-10.198$ & 0.032 \\
\hline
\end{tabular}

\begin{tabular}{llll}
\hline Variable & Hazard & $95 \%$ CI & $p$-value \\
\hline PIM probability of death $(\%)$ & 0.971 & $0.913-1.033$ & 0.356 \\
Mean TISS-28 first 48 $\mathrm{h}$ & 1.006 & $0.989-1.023$ & 0.505 \\
Pre-transfusion Hb concentration (mmol/l) & 1.004 & $0.335-3.004$ & 0.995 \\
Post-operative admission (yes/no) & 0.782 & $0.486-1.257$ & 0.310 \\
Presence of sepsis/malignancy (yes/no) & 0.981 & $0.897-1.073$ & 0.672 \\
RBC transfusion & 2.661 & $1.491-4.746$ & 0.001 \\
\hline
\end{tabular}

from Fig. 1. Mortality rates were equally distributed a dose-outcome association between the number of RBC among patients with a $\mathrm{Hb}<9 \mathrm{~g} / \mathrm{dl}$ or $\geq 9 \mathrm{~g} / \mathrm{dl}$ [2 of 36 transfusions and mortality $(p=0.002)$, which is depicted $(5.6 \%)$ vs. 14 of $225(6.2 \%), p=\mathrm{NS})]$. This was also noted in Fig. 2.

for patients with a $\mathrm{Hb}<7 \mathrm{~g} / \mathrm{dl}$ or $\geq 7 \mathrm{~g} / \mathrm{dl}[1$ of $7(14.3 \%)$

Additionally, transfused patients required prolonged vs. 15 of $254(5.9 \%), p=\mathrm{NS}$; ; however, we did observe ventilatory support $(11.1 \pm 1.8 \quad$ vs. $3.2 \pm 0.3$ days, 
Fig. 3 Standardized mortality rate $(S M R)$ of transfused and non-transfused patients according to five PIM probability of death strata. The SMR is calculated by dividing the number of observed deaths by the number of expected deaths. The number of expected deaths was obtained from the Dutch Working Group on Pediatric Intensive Care Evaluation (PICE). N/A, not applicable
Table 6 Results from the Cox proportional hazards regression analysis on the association between RBC transfusion and duration of PICU stay $(n=278$ patients). Adjustments were made for age, PIM probability of death, mean TISS-28 score during the first $48 \mathrm{~h}$ of PICU admission, post-operative admission, presence of sepsis or malignancy, and pre-transfusion hemoglobin concentration.

$\beta$, coefficient's estimate;

$C I$, confidence interval

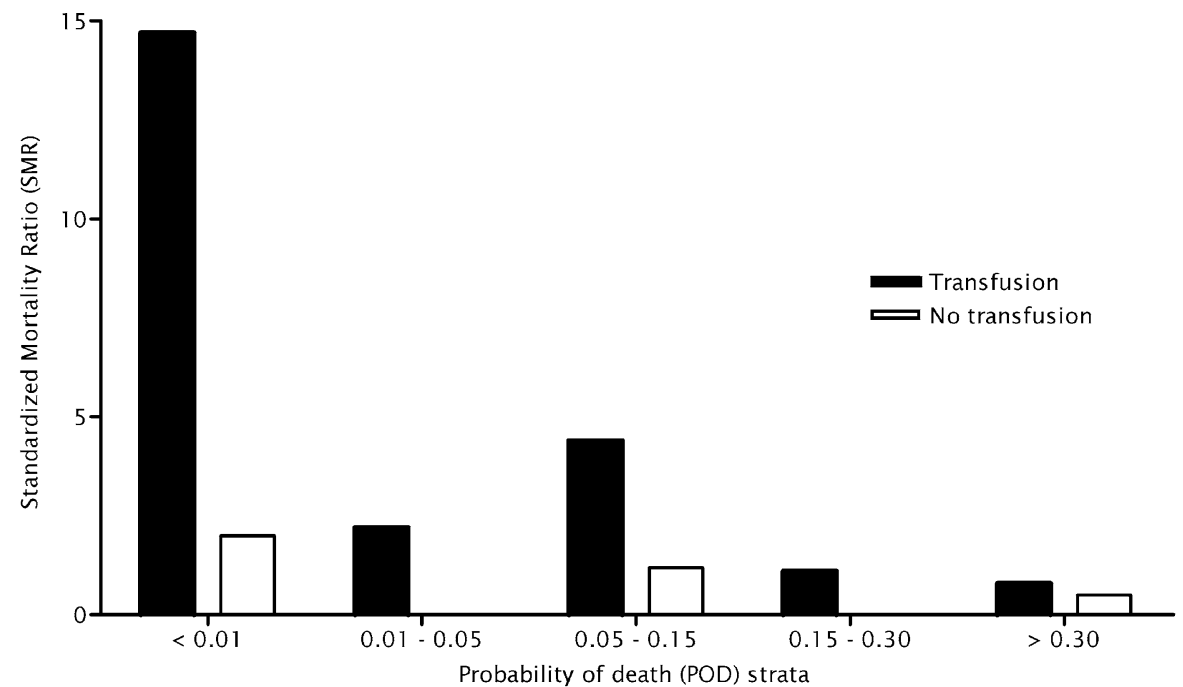

$\mathrm{N}=3 / 9$
$\mathrm{~N}=1 / 11$
$8.1 \%$
1.6
$/(.081 * 9)=$
4.4
1.1

1.1

$\mathrm{N}=1 / 5$
$\mathrm{~N}=0 / 3$
$20.4 \%$
1.6
$1 /(.204 * 5)=$
1.1
$\mathrm{~N} / \mathrm{A}$

$N=1 / 3$

$\mathrm{N}=1 / 5$

$57.1 \%$

4.6

$1 /(.571 * 3)=$ .8

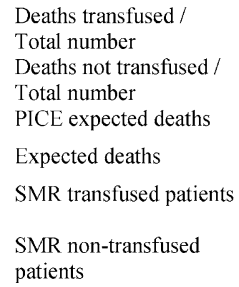

$\begin{array}{cc}\mathrm{N}=4 / 17 & \mathrm{~N}=2 / 33 \\ \mathrm{~N}=4 / 127 & \mathrm{~N}=0 / 82 \\ .5 \% & 2.3 \% \\ .72 & 2.6 \\ 4 /(.005 * 17)= & 2 /(.023 * 33)= \\ 47.1 & 2.2 \\ 2.0 & \mathrm{~N} / \mathrm{A}\end{array}$

Variable

PIM probability of death $(\%)$

Mean TISS-28 first $48 \mathrm{~h}$

Pre-transfusion $\mathrm{Hb}$ concentration $(\mathrm{mmol} / \mathrm{l})$

Post-operative admission (yes/no)

Presence of sepsis/malignancy (yes/no) RBC transfusion

\begin{tabular}{llr}
1.013 & $0.965-1.062$ & 0.609 \\
3.017 & $1.941-4.691$ & $<0.001$ \\
\hline
\end{tabular}

$p<0.001$ ), and prolonged infusion of vaso-active agents $(8.2 \pm 1.8$ vs. $2.8 \pm 0.6$ days, $p<0.01)$. Finally, a prolonged PICU stay $(13.0 \pm 1.8$ vs. $3.2 \pm 0.2$ days, $p<0.001$ ) among transfused patients was found.

Fig. 3 shows the SMR among transfused and nontransfused children for the PIM probability of death. We observed an excess mortality among transfused children, especially when they had a very low to moderate probability of death. Similar observations were made among children with a high probability of death, but the numbers of patients was limited in these strata.

In additional analyses-one excluding patients admitted after a surgical procedure, one excluding patients with a PICU stay less than 2 days were excluded, and one excluding patients with a high-risk diagnosis (sepsis or malignancy)—we also noted significant differences in mortality, duration of MV, duration of vaso-active support, and PICU stay between transfused and non-transfused patients (Table 2). Also, when excluding children older than 12 months similar observations between RBC transfusion and increased morbidity were made.

\section{Multivariate analysis}

Tables 3-6 summarize the results from the adjusted multivariate logistic regression analysis on the primary outcome measure, and Cox regression analysis on the association between RBC transfusion and the secondary outcome measures. Adjustments were made for PIM 
probability of death, mean TISS-28 score during the first $48 \mathrm{~h}$ of PICU admission, post-operative admission, presence of sepsis and/or malignancy, and pre-transfusion $\mathrm{Hb}$ concentration. From the multivariate logistic regression analysis it was found that RBC transfusion was the strongest variable associated with mortality rather than disease severity reflected by the PIM probability of death, mean TISS-28, or the pre-transfusion Hb concentration (Table 3). After adjusting for possible confounding by PIM probability of death and mean TISS- 28 score during the first $48 \mathrm{~h}$ of PICU admission, post-operative admission, and pre-transfusion $\mathrm{Hb}$ concentration, it was found that RBC transfusion was independently associated with a prolonged duration of vaso-active support (Table 3), mechanical ventilation (Table 4), and PICU stay (Table 5).

\section{Discussion}

In this observational study we have found that RBC transfusion in a heterogeneous group of critically ill children was independently associated with increased mortality and morbidity. Furthermore, we observed a higher mortality rate in patients with multiple transfusions but could not find a difference in mortality and pre-transfusion $\mathrm{Hb}$ concentration. Excess mortality was found among transfused patients, especially when they were less severely ill as defined by a low PIM probability of death. Similar observations were found when patients admitted after a surgical procedure or patients with a PICU stay less than 2 days were excluded from analysis. The strength of our study is that with a relatively small number of patients such a strong association was found. Although there are numerous data for adults on this subject, to our knowledge, we are the first to report an association between RBC transfusion and mortality in critically ill children.

The findings of this study are in agreement with the observations by Goodman et al. [4]. In this retrospective cohort study of five PICUs, patients with a pre-transfusion $\mathrm{Hb}$ concentration less than $9 \mathrm{~g} / \mathrm{dl}$ admitted between 1996 and 1999 were studied. They found an increased duration of mechanical ventilation, duration of infusion of vasoactive agents, and prolonged PICU stay among transfused children. Although in their study mortality rates were higher in the transfused group (6.9 vs. $0.9 \%)$, the number of deaths were too low ( 9 in the transfused group and only 1 in the non-transfused group) to study mortality in a multivariate analysis. However, our study was methodologically different compared with the study by Goodman et al. [4]. Because patients with a pre-transfusion $\mathrm{Hb}$ greater than $9 \mathrm{~g} / \mathrm{dl}$ are also (often) transfused, we included all patients irrespective of the pre-transfusion $\mathrm{Hb}$ value $[3,17]$. With this inclusion method we not only support the observations by Goodman et al. [4] but also observed an even stronger association, adding more strength to our study.
Our observations are also in agreement with those made in a heterogeneous group of critically ill adults [6-16]. In a large prospective observational study among 1136 critically ill adults admitted to 145 western European ICUs it was found in multivariate analysis that mortality was independently associated with erythrocyte transfusions, irrespective of admitting SOFA or APACHE II score [14]. These observations followed up on the results of a multicenter, randomized controlled trial including 838 critically ill patients with a $\mathrm{Hb}$ less than $9 \mathrm{~g} / \mathrm{dl}$, investigating the effect of a restrictive transfusion strategy (transfusion if the $\mathrm{Hb}$ dropped below $7 \mathrm{~g} / \mathrm{dl}$ ) compared with a liberal transfusion strategy (transfusion if the $\mathrm{Hb}$ dropped below $10 \mathrm{~g} / \mathrm{dl}$ ) [7]. Overall mortality and length of ICU stay were comparable between the two treatment arms, indicating that it was safe to apply a restrictive transfusion strategy. Additional analysis demonstrated that in patients with an APACHE II score less than 20 or patients younger than 55 years mortality was significantly increased among those randomized to the liberal transfusion strategy. In contrast to the above-mentioned studies, Vincent and co-workers were unable to detect an independent association between RBC transfusion and increased mortality in 3147 critically ill adults enrolled in the SOAP study [15]. This disagreement in findings cannot be easily explained.

Although we have found a strong association, it is more difficult to ascertain a causative relationship with respect to pathophysiological mechanisms. It is suggested that RBC transfusions are associated with immunosuppressive effects and the development of multiple system organ failure [12, 21, 22]. It is assumed that leukocytes present in donor blood are responsible for this immunomodulation. Studies performed in critically ill or injured patients showing increased morbidity and mortality mainly used leukocyte-non-depleted standard or buffy-coat RBC preparations $[7,12,14,21]$. It therefore seems reasonable to advocate the use of leukocyte-depleted preparations, although the effect of these preparations on patient outcome is not free from scientific debate [21, 23]. Interestingly, despite the fact that patients in our study were transfused with leukocyte-depleted RBCs, we still found increased mortality and morbidity independently associated with erythrocyte transfusion. Additionally, we have observed a dose-outcome relationship between the number of RBC transfusions and mortality (Fig. 2) instead of a relationship between pre-transfusion $\mathrm{Hb}$ concentration and mortality (Fig. 1). Such a relationship has also been found to be an independent predictor for post-operative infections, suggesting a dose-relationship between erythrocyte transfusion and increased morbidity [8]. Our data suggest that the presence of anemia itself has no effect on mortality, although the lack of difference in mortality for patients with a low $\mathrm{Hb}$ might be influenced by the fact these patients are probably more easily transfused. This observation is in contrast to 
findings by Corwin et al. [6]. They observed that anemia was an independent predictor for mortality among 4892 critically ill adults enrolled in a multi-center observational cohort study. This difference is most likely differences in methodology. We have used the first $\mathrm{Hb}$ concentration when patients were not transfused rather than using the nadir $\mathrm{Hb}$ for analysis. Additionally, but more speculatively, children might adapt more easily to anemia than adults.

Treatment of anemia is the main rationale for transfusing critically ill children. It is often thought that systemic oxygen consumption will be improved in critically ill children when they are transfused; however, this concept has never been proven [17]. In our study we found that $13.4 \%$ of the patients had a $\mathrm{Hb}$ below $9.7 \mathrm{~g} / \mathrm{dl}$. Also, our transfusion rate is in accordance with previously reported numbers by others [3]. Based upon this study we advocate further investigations aimed at defining a suitable and safe threshold value for $\mathrm{Hb}$ used in the decision as to when to transfuse a critically ill child, stratifying for age, disease severity, and co-morbidities. At present, such studies are unavailable but eagerly awaited [24]. From two surveys among pediatric intensivists comprising four scenarios from daily clinical practice, it became clear that there is a striking variation in $\mathrm{Hb}$ threshold to transfuse patients, especially among children after cardiac surgery or children with sepsis $[2,17]$. This was confirmed by a prospective, descriptive single-center study demonstrating that cardiac disease, severe critical illness defined by admission PRISM score $>10$, and multiple organ dysfunction syndrome (MODS) were independent determinants for the decision to transfuse critically ill children [3].

Some limitations of our study must also be mentioned. Firstly, its retrospective character could have influenced the availability of the data collected. Nonetheless, data on both primary and secondary outcomes could be retrieved for all included patients. Also, because of its retrospective character, the decision to transfuse was at the discretion of the attending physician. The decision to transfuse is often made on a subjective basis when no transfusion policy is available. Subjective criteria often include being on a ventilator or on vaso-active support. This leads to confounding by indication (i. e., severely ill patients or patients with a low $\mathrm{Hb}$ are more easily transfused), a matter that can ultimately only be resolved by a randomization, although regression analysis also minimizes confounding in cohort studies [20]. However, in order to minimize the effect of confounding by indication, we have adjusted our observations for the mean TISS-28 score during the first $48 \mathrm{~h}$ of admission. TISS-28 accounts for therapeutic and monitoring interventions, and correlates with nursing manpower. By doing so, we have attempted to substitute the subjective decision to transfuse a patient with the TISS-28 because it comprises parameters that are also often used by the attending physician in the decision making.

Secondly, our study reflects a single-center experience. This may limit the generalizability of our study, although our PICU is most likely comparable to other European and North American PICUs. Additionally, our patient group is a heterogeneous group of critically ill children, although this is not different from many adult studies $[6,7,14,16]$. Furthermore, because of the relatively small number of patients, no stratification could be made to study the effect RBC transfusions in a specific kind of illness such as sepsis.

Thirdly, we did not incorporate data on organ dysfunction upon PICU admission as a variable itself in the multivariate model. We feel that the presence of organ dysfunction noted only upon PICU admission, instead of daily assessment, may be less predictive for outcome of the patient.

Fourthly, in addition to a full multivariate logistic regression analysis, we also performed bivariate logistic regression analysis because the number of outcome events per independent variable (EPV) might be too low, resulting in a unreliable model [25]. Importantly, as with any multivariate analysis, causality between an event and the outcome cannot be fully determined, as there might very well be a confounder that is associated with the outcome that has not been detected by, for instance, the PIM probability of death or mean TISS-28.

Finally, RBC transfusions prior to PICU admission but related to the current condition of the patient, for instance, transfusions in the operating room, were not included in the analysis; however, in an attempt to eliminate this possible confounding, we performed an additional analysis excluding patients who were admitted after a surgical procedure. From this analysis we observed similar independent associations between RBC transfusion and mortality and morbidity.

\section{Conclusion}

In this retrospective single-center cohort study $\mathrm{RBC}$ transfusion was independently associated with increased mortality and prolonged duration of mechanical ventilation, infusion of vaso-active agents, and PICU stay. Higher mortality rates were found among patients with multiple transfusions. Our observations, although they should by confirmed by others, warrants the identification of a suitable and safe threshold value for hemoglobin to determine when to transfuse critically ill children.

Acknowledgements. The authors thank Prof. Dr. A.B.J. Groeneveld for his careful review of the manuscript. 


\section{References}

1. Gauvin F, Chaibou M, Leteurte S, Toledano B, Hume H (2000) Transfusion de concentré globulaire en réanimation pédiatrique. Réanim Urgences 9:339-344

2. Nahum E, Ben Ari J, Schonfeld T (2004) Blood transfusion policy among European Pediatric Intensive Care Physicians. J Intensive Care Med 19:38-43

3. Armano R, Gauvin F, Ducruet T, Lacroix J (2005) Determinants of red blood cell transfusions in a pediatric critical care unit: a prospective, descriptive epidemiological study. Crit Care Med 33:2637-2644

4. Goodman AM, Pollack MM, Patel KM, Luban NL (2003) Pediatric red blood cell transfusions increase resource use. J Pediatr 142:123-127

5. Mhanna MJ, Super DM (2005) What hemoglobin value should one use in transfusing a critically ill child? Crit Care Med 33:2710-2711

6. Corwin HL, Gettinger A, Pearl RG, Fink MP, Levy MM, Abraham E, MacIntyre NR, Shabot MM, Duh MS, Shapiro MJ (2004) The CRIT Study: anemia and blood transfusion in the critically ill: current clinical practice in the United States. Crit Care Med 32:39-52

7. Hebert PC, Wells G, Blajchman MA, Marshall J, Martin C, Pagliarello G, Tweeddale M, Schweitzer I, Yetisir E (1999) A multicenter, randomized, controlled clinical trial of transfusion requirements in critical care. Transfusion Requirements in Critical Care Investigators, Canadian Critical Care Trials Group. N Engl J Med 340:409-417

8. Hill GE, Frawley WH, Griffith KE, Forestner JE, Minei JP (2003) Allogeneic blood transfusion increases the risk of postoperative bacterial infection: a meta-analysis. J Trauma 54:908-914
9. Koch CG, Khandwala F, Li L, Estafanous FG, Loop FD, Blackstone EH (2006) Persistent effect of red cell transfusion on health-related quality of life after cardiac surgery. Ann Thorac Surg 82:13-20

10. Koch CG, Li L, Duncan AI, Mihaljevic T, Loop FD, Starr NJ, Blackstone EH (2006) Transfusion in coronary artery bypass grafting is associated with reduced long-term survival. Ann Thorac Surg 81:1650-1657

11. Koch CG, Li L, Duncan AI, Mihaljevic T, Cosgrove DM, Loop FD, Starr NJ, Blackstone EH (2006) Morbidity and mortality risk associated with red blood cell and blood-component transfusion in isolated coronary artery bypass grafting. Crit Care Med 34:1608-1616

12. Moore FA, Moore EE, Sauaia A (1997) Blood transfusion. An independent risk factor for postinjury multiple organ failure. Arch Surg 132:620-624

13. Palmieri TL, Caruso DM, Foster KN, Cairns BA, Peck MD, Gamelli RL, Mozingo DW, Kagan RJ, Wahl W, Kemalyan NA, Fish JS, Gomez M, Sheridan RL, Faucher LD, Latenser BA, Gibran NS, Klein RL, Solem LD, Saffle JR, Morris SE, Jeng JC, Voigt D, Howard PA, Molitor F, Greenhalgh DG (2006) Effect of blood transfusion on outcome after major burn injury: a multicenter study. Crit Care Med 34:1602-1607

14. Vincent JL, Baron JF, Reinhart K, Gattinoni L, Thijs L, Webb A, Meier-Hellmann A, Nollet G, PeresBota D (2002) Anemia and blood transfusion in critically ill patients J Am Med Assoc 288:1499-1507

15. Vincent JL, Sakr Y, Le Gall JR, Gerlach H, Reinhart K, Sprung C, Moreno R, Carlet J, Ranieri M, Payen D (2003) Is red blood cell transfusion associated with worse outcome? Results of the SOAP Study. Chest 124:125S-125a
16. Gong MN, Thompson BT, Williams P, Pothier L, Boyce PD, Christiani DC (2005) Clinical predictors of and mortality in acute respiratory distress syndrome: potential role of red cell transfusion. Crit Care Med 33:1191-1198

17. Laverdiere C, Gauvin F, Hebert PC, Infante-Rivard $\mathrm{C}$, Hume $\mathrm{H}$, Toledano BJ, Guertin MC, Lacroix J (2002) Survey on transfusion practices of pediatric intensivists. Pediatr Crit Care Med 3:335-340

18. Shann F, Pearson G, Slater A, Wilkinson K (1997) Paediatric index of mortality (PIM): a mortality prediction model for children in intensive care. Intensive Care Med 23:201-207

19. Miranda DR, de Rijk RA, Schaufeli W (1996) Simplified Therapeutic Intervention Scoring System: the TISS-28 items: results from a multicenter study. Crit Care Med 24:64-73

20. Normand SL, Sykora K, Li P, Mamdani M, Rochon PA, Anderson GM (2005) Readers guide to critical appraisal of cohort studies: 3 . Analytical strategies to reduce confounding. Br Med J 330:1021-1023

21. Silliman CC, Moore EE, Johnson JL, Gonzalez RJ, Biffl WL (2004) Transfusion of the injured patient: proceed with caution. Shock 21:291-299

22. Vamvakas EC, Blajchman MA (2001) Deleterious clinical effects of transfusion-associated immunomodulation: Fact or fiction? Blood 97:1180-1195

23. Vincent JL, Piagnerelli M (2006) Transfusion in the intensive care unit. Crit Care Med 34:S96-S101

24. Mhanna MJ, Super DM (2005) What hemoglobin value should one use in transfusing a critically ill child? Crit Care Med 33:2710-2711

25. Concato J, Feinstein AR (1997) Monte Carlo methods in clinical research: applications in multivariable analysis. J Invest Med 45:394-400 